\title{
HIV/AIDS in Migrant People of Dang District of Nepal
}

\author{
Karna Bahadur Oli ${ }^{1}$ and Mahendra Maharjan ${ }^{2}$ \\ Central Department of Zoology, Tribhuvan University, Kirtipur, Kathmandu, Nepal \\ Email: 'karna_oli2007@yahoo.com \&2maharjan.m@gmail.com
}

\begin{abstract}
Present status of HIV/AIDS among the migrant people of Dang district along with Knowledge, Attitude and Practices (KAP) was assessed by blood testing and questionnaire survey. A total of 1102 blood samples from migrants as well as spouse of migrants were tested for HIV using Rapid Diagnostic Test (RDT) kits as recommended by national HIV testing protocol. The overall HIV prevalence was found to be $0.6 \%$ in Dang district during the year $2012-2013$. Migrants and spouse of migrants were infected in the equal ratio $(0.3 \%)$. Maximum of the participants were among the age group 18-34 years and most of them had attained lower secondary level education. Maximum (97.3\%) respondents had knowledge about the family planning methods and practice of condom use among the married population was also satisfactory. About $16 \%$ of the participants had expressed their practice of sexual relationship outside more than once, which signifies vulnerability to HIV infection. Maximum married females were suffered from Sexually Transmitted Infections (STI) which may lead to infection such as Syphilis and HIV/AIDS.
\end{abstract}

Keywords: Prevalence, HIV/AIDS, KAP, migrants, Dang district, VCT centre.

\section{INTRODUCTION}

Human Immuno-deficiency Virus (HIV) is a lentivirus (slowly replicating virus) that causes Acquired Immunodeficiency Syndrome (AIDS) (Douek et al. 2009) a condition in humans in which progressive failure of the immune system allows life threatening opportunistic infections and cancers to thrive. AIDS has become one of the world's most serious health and development challenges. The first case was reported in 1981 and today more than 30 years later, approximately 34 million people currently living with HIV and nearly 30 million people have died of AIDS related causes since the beginning of the epidemic (UNAIDS 2012). People who inject drugs, men who have sex with other men and female sex workers are the key high risk population groups spreading the epidemic. Most new infections are transmitted heterosexually although risk factors vary.

The main transmission mode of HIV in Nepal has been through sexual transmission (UNGASS 2010). Women in Nepal, including women in sex work and wives of migrants, are at especially high risk. Nepali migrants working in India were engaged in high risk sexual behaviour and frequently visited brothels or sex workers so migrants are considered the most vulnerable subset of the population and represent a significant bridge population that contributes to the spread of the HIV epidemic (Wasti et al. 2009). Mostly migration for employment purpose found to be almost in all developing and developed countries but with regard to HIV/AIDS, no data were found to be recorded. The only available data regarding HIV/AIDS among migrants are available among those who frequently migrate to India. Besides these data remaining HIV/AIDS among migration is from internal migration (FHI \& New Era 2001; Poudel et al. 2006).

Geographically landscape of Nepal is widely varied from Mountain to Terai. Terai is more developed than other parts so hilly and mountain people migrate to Terai, headquarters for employment where one of the growing business is commercial sex or prostitution. Hence ordinary people from hilly as well as Terai involve in sexual activities with these prostitutes as a result they become infected by HIV/AIDS (Poudel 2001)

HIV/AIDS was first recorded in Dang in 2005 from the Voluntary Counseling and Testing (VCT) centre of Nepal family planning Association Dang Branch. In 2006, 13 males and nine females were confirmed in which eight males and one female were dead. At the end of 2012 April there were altogether 173 people infected among which 75 were migrants and 34 males and 12 females were dead from HIV/AIDS (DACC, Dang 2012) indicating increasing trends of HIV/AIDs in this district. Generally migrants carry the HIV/AIDS and transmitted to their spouse. Hence the study aimed to explore the present status of HIV/AIDS among migrants and their spouse in Dang district.

\section{MATERIALS AND METHODS}

The present study was carried out in two VCT centers established by Dang Plus, a Non Government Organization working in the field of HIV/AIDS/STIs 
awareness and prevention particularly on the migrants people in Dang district. Lamahi VCT centre in the east of district covers $11 \mathrm{VDC}$ and Tulsipur VCT centre in west covering $28 \mathrm{VDC}$ and two municipalities.

The study was divided into two parts: First part: Blood examination and Second part: Questionnaire survey. After obtaining the written consent from the study participants, blood collection was done by two methods: vein puncture and finger prick method. Ethical approval was obtained from Nepal Health Research Council. The HIV antibody tests were performed using three different types of immuno-chromatography or Rapid kits that were recommended by the national HIV testing protocol and followed UNAIDS and WHO HIV Test Surveillance / Diagnosis Algorithm Strategy II. Determine HIV 1/2 Kits (Abott, Japan Co. Ltd) were used as the first line of screening test. Uni-Gold HIV 1/2 Kits (Trinty Biotech, Dublin, Ireland) were used as confirmatory test and SD Bioline HIV 1/2test kits ( Standard Diagnostics Inc.,
Kyonggii-do South Korea) were used as tie- breaker for unresolved results from first line of screening and confirmatory tests. After lab analysis each participant were given result of the test by counselor with confidentiality. Questionnaires survey was carried out from randomly selected 150 participants by using structured, pretested and tested questionnaire.

\section{RESULTS}

\section{HIV situation among migrant population}

The overall HIV prevalence was found to be $0.6 \%$ in Dang district during the year $2012-2013$. Among the different age group 25-34 has the highest prevalence $(0.3 \%)$ compared to other age group. This is the most potential reproductive age group and has shown the significant association with the HIV $(\mathrm{P}<0.05)$. Sex wise analysis of HIV among migrant population revealed maximum in males $(1.8 \%)$ in comparison to female $(0.3 \%)$, which is statistically significant $(\mathrm{p}<0.05)$ (Table 1$)$.

Table 1. HIV Prevalence in different Age and Sex group

\begin{tabular}{|c|c|c|c|c|c|c|}
\hline \multirow{2}{*}{$\begin{array}{l}\text { Age category } \\
\text { (Years) }\end{array}$} & \multicolumn{3}{|c|}{ Sex } & \multirow[b]{2}{*}{ HIV +ve } & \multirow{2}{*}{ Total } & \multirow{2}{*}{ HIV +ve } \\
\hline & Male & HIV +ve & Female & & & \\
\hline $1-17$ & $6(2.7 \%)$ & $1(0.5 \%)$ & $12(1.1 \%)$ & 0 & $18(1.6 \%)$ & $1(0.1 \%)$ \\
\hline $18-24$ & $69(31 \%)$ & 0 & $329(29.9 \%)$ & 0 & $398(36.1 \%)$ & 0 \\
\hline $25-34$ & $99(44 \%)$ & $1(0.5 \%)$ & $383(34.8 \%)$ & $2(0.2 \%)$ & $482(43.7 \%)$ & $3(0.3 \%)$ \\
\hline $35-44$ & $30(2.7 \%)$ & $1(0.5 \%)$ & $134(12.2 \%)$ & $1(0.1 \%)$ & $164(14.9 \%)$ & $2(0.2 \%)$ \\
\hline $45-75$ & $17(1.5 \%)$ & $1(0.5 \%)$ & $23(2.1 \%)$ & 0 & $40(3.6 \%)$ & $1(0.1 \%)$ \\
\hline Total & $221(20.1 \%)$ & $4(1.8 \%)$ & $881(79.9 \%)$ & $3(0.3 \%)$ & 1102 & $7(0.6 \%)$ \\
\hline
\end{tabular}

After migrant populations, their spouses are second leading risk group with regards to HIV infection. The result revealed that only the male migrant people $(1.3 \%)$ and their spouse $(0.3 \%)$ were found to be positive for HIV while none of female migrants and their spouse were found to be infected. In general prevalence rate of HIV in both migrant population and their spouses were same $(0.3 \%)$. During the study a case $(0.1 \%)$ of Mother to child transmission (MTCT) had been recorded (Table 2).

Table 2. Prevalence of HIV in different Risk group and Sex group

\begin{tabular}{|c|c|c|c|c|c|c|}
\hline \multirow[t]{2}{*}{ Risk group } & \multicolumn{4}{|c|}{ Sex } & \multirow[t]{2}{*}{ Total } & \multirow[t]{2}{*}{ HIV +ve } \\
\hline & Male & HIV +ve & Female & HIV +ve & & \\
\hline Migrant & $215(19.5 \%)$ & $3(1.3 \%)$ & $6(0.5 \%)$ & 0 & $221(20.1 \%)$ & $3(0.3 \%)$ \\
\hline Spouse of migrant & $4(0.4 \%)$ & 0 & $875(79.4 \%)$ & $3(0.3 \%)$ & $879(79.8 \%)$ & $3(0.3 \%)$ \\
\hline MTCT & $2(0.2 \%)$ & $1(0.4 \%)$ & 0 & 0 & $2(0.2 \%)$ & $1(0.1 \%)$ \\
\hline Total & $221(20.1 \%)$ & $4(1.8 \%)$ & $881(79.9 \%)$ & $3(0.3 \%)$ & & $7(0.6 \%)$ \\
\hline
\end{tabular}

Knowledge, attitude and practice (KAP) of HIV among migrant population

A total of 150 migrant populations were surveyed using structured questionnaires for the KAP. Maximum people (96\%) have knowledge about HIV and its testing facility at VCT centers of Dang Plus, a NGO working in HIV/AIDS in Dang. But regarding the knowledge of other sexually transmitted diseases (STIs) and their preventive measures was not found to be satisfactory. Most of the participants had attained lower secondary level education while about $(50 \%)$ of the participants have misconceptions about transmission of HIV such as by sharing same utensil/toilet/ clothes /swimming pool 
as well as kissing besides major modes of transmission (98.7\%) through unsafe sexual practice and sharing same injecting equipments.

In relation to the target population and their condom use practice, the result revealed that the spouse of migrants (38\%) used condom sometimes in last 12 months while
$18.7 \%$ migrant used condom sometimes in last 12 months. Similarly $4 \%$ migrant and $7.3 \%$ spouse of migrant never used condom in last 12 months. It is shown that there was statistically significant association between condom use practice by migrant population as well as their spouses ( $\mathrm{p}$ $<0.05$ ) (Table 3).

Table 3. Target group and condom use among study participants

\begin{tabular}{|l|c|c|c|c|c|}
\hline \multirow{2}{*}{ Target group } & \multicolumn{4}{|c|}{ Condom use in last 12 months } & \multirow{2}{*}{ Total } \\
\cline { 2 - 6 } & Never & Sometimes & $\begin{array}{c}\text { Not sexually active in last } \\
12 \text { months }\end{array}$ & $\begin{array}{c}\text { Other method of } \\
\text { contraception }\end{array}$ & $3(2 \%)$ \\
\hline Migrant & $6(4 \%)$ & $28(18.7 \%)$ & $3(2 \%)$ & $18(12 \%)$ & $110(73.3 \%)$ \\
\hline Spouse of migrant & $11(7.3 \%)$ & $57(38 \%)$ & $24(16 \%)$ & $21(14 \%)$ & 150 \\
\hline Total & $17(11.3 \%)$ & $85(56.7 \%)$ & $27(18 \%)$ & $26.7 \%)$ \\
\hline
\end{tabular}

Sexual relationship and marital status among participants showed 16\% married people had sexual relationship with other paying partners. Similarly $76.7 \%$ were not involved in sexual relationship outside. On the other hand $4 \%$ unmarried people had sexual relationship with other paying partners, which showed statistically significant association between sexual relationship and marital status $(\mathrm{p}<0.05)$. Maximum male migrant people $(72.5 \%)$ had shown to be involved in sexual relationship with other paying partners.

\section{DISCUSSION}

Migration of people play key role in the import and dissemination of HIV in the world including Nepal. Particularly in developing countries like Nepal, people frequently migrate for work and other economic related activities within the country or beyond the boundary of the country. Large number of international labour migration statistic indicates, various Indian cities are the common destination due to open boarder and easy access. A study done among Nepalese migrant workers working in Nepal and Indian cities by Gurubacharya and Gurubacharya (2004) showed HIV prevalence of 2.3\% among migrants with in Nepal and $8.5 \%$ among migrants to India indicating the alarming situation of HIV import from India. Similarly in between migrant and non migrants people, higher HIV prevalence was reported among migrants (Poudel 2001, FHI 1999), which showed migrants are the high risk groups contracting HIV. Iredale et al. (2005) reported more than $80 \%$ HIV positive population between age group 20-39 which is the economically productive and sexually active group supporting our present findings.

Both external as well as internal migrations have great impact in dissemination of HIV in the community. Prevalence rate of HIV among external migrants $7.7 \%$ among people migrating from Achham to Mumbai by FHI and New Era, (2001) and similar result shown by World Bank and UNAIDS (2009) were critical. Similarly another report showed $0.6 \%$ of HIV/AIDS among people migrated from Kailali to Uttar Pradesh (Poudel et al. 2006) which was similar to the result shown by FHI and New Era 2001 in Sandepani and Darakh VDC of Kailali.

One of the report showed people among hilly district (Doti) have HIV/AIDS (2\%) which is clear that it was from the internal migration (Poudel 2001). Many research reports showed that HIV prevalence is higher among migrants than non migrants. A research done in Doti shows $10.10 \%$ and $2 \%$ (Poudel 2001) in migrant and non migrant was similar to the result of truckers (migrants) along the highway routes in the Terai of Nepal (FHI 1999). Similarly prevalence of HIV among migrants returnees from Mumbai in 2005 showed 46\% of the estimated infection in Nepal were among seasonal labour migrants to India (UNAIDS 2008). Prevalence of HIV among people of Far Western to India in seasonal migration showed increasing trend of prevalence with year (Vaidya \& Jianhong 2007). HIV/AIDS among male labour migrant workers in Western Development Region and Far Western Development Region showed 1.4\% and $0.8 \%$ respectively (New Era and SACTS 2008) which was lower than migrant workers working in Nepal and Indian cities (Gurubacharya \& Gurubacharya 2004).

Prostitution is illegal and hidden business in most of the country. Research on KAP study among migrant workers working in Nepal and Indian cities showed $60 \%$ of migrants within Nepal and $85 \%$ of migrants to India have visited Female sex workers (FSWs), $75 \%$ of migrant within Nepal used condom while visiting FSWs in comparison to only $10 \%$ of migrants to India (Gurubacharya \& Gurubacharya 2004). An IBBS 
study showed the prevalence of HIV among the wives of migrants laborers (who temporarily migrate or had migrated to India) in the West to Far Western region of Nepal is 3.3\% and varies with four districts, $4.5 \%$ in Achham, 3\% in Doti , $2.5 \%$ in Kailai and $1.1 \%$ in Kanchanpur (New Era \& SACTS 2008). Prevalence of HIV among trafficked women returning from India to Nepal showed 22\% to 38\% (Silverman et al. 2007).

Age and sex wise distribution of participants showed maximum participants were female (76\%) compared to male (24\%) and among the age group 18-34 years which was higher than the study done in Kanchanpur district by Sharma (2005) in which females were $60 \%$. Almost similar prevalence rate of HIV revealed in between male migrants and the spouse of the male migrant people indicated that male migrants are key sources of HIV carrier which is disseminated in the community through their spouse. Further, only the male migrants and their spouse are at the high risk of contracting the HIV, not the female migrants and their spouse. Trends of HIV testing and counseling in VCT centre of Dang plus showed maximum (75.3\%) among married females whose spouse were labour migrant within or outside the country similar to the previous studies (Ghimire 2004; Rai 2005; Sharma 2005; He et al. 2009).

Although maximum participants were aware about the family planning methods as well as heard about the HIV/AIDS (Bartoula, 2004; Karki 2005; Rai 2005; Chaudhari 2005; and He et al. 2009) misconception about transmission of HIV/AIDS among 50\% of participants were high enough as indicated by Myanmar migrants in Thailand by Thu et al. (2004). More than $90 \%$ participants believed that multiple sex partners is one of the risk of getting HIV/AIDS. Educational level and condom use among participants was statistically significant in the present study which was similar to the KAP study done in Cyprus by Kouta et al. (2013); however Thu et al. (2004) showed insignificant association between knowledge and condom use. The present study showed $72.5 \%$ of migrants involved in sexual relationship with other paying partners which was higher than the work done by Gurubacharya \& Gurubacharya (2004) $(60 \%)$ indicating male migrants are more vulnerable to HIV infection than female.

\section{ACKNOWLEDGEMENTS}

The authors are greatly thankful to Prakash Nepali (Program Director of Dang Plus) and all the staff of Dang Plus, Dang for their enthusiastic support during the research work.

\section{REFERENCES}

Bartoula, K. 2004. Impact of mass media on Knowledge of HIV/AIDS and STDs among migrant female carpet workers: a study of Kathmandu valley. MA Thesis. Central Department of Population Studies, Tribhuvan University, Kathmandu, Nepal.

Bhusal, H.N. 2005. Knowledge, Attitude and Behaviour on STDs and HIV/AIDS among Secondary level school students: a case study of some selected secondary school in Eastern part of Nawalparasi district. MA Thesis. Central Department of Population Studies, Tribhuvan University, Kathmandu, Nepal.

Chaudhari, S.K. 2005. Knowledge, Attitude and Behaviour towards sexually transmitted disease, HIV/AIDS and use of condom among males who were ever emigrant workers: a case study of some V.D.Cs. of Saptari district. MA Thesis. Central Department of Population Studies, Tribhuvan University, Kathmandu, Nepal.

DACC. 2012. District AIDS Profile, Government of Nepal. District AIDS Co-ordination Committee, Dang.

DOHS. 2012. Annual Report 2067/68 (2010/2011). Department of Health Services, Ministry of Health and Population, Kathmandu, Nepal.

Douek, D.C., Raedever, M. and Koup, R.A. 2009. Emerging concepts in the immunopathogenesis of AIDS. Annual Revised Medicine 60: 471-484.

FHI, 1999. STD and HIV prevalence survey among female sex workers and truckers on highway routes in the Terai, Family Health International, Nepal.

FHI and New Era. 2001. A study in Prevalence and risk factors among migrant and non migrants of Kailai district. Family Health International and New Era, Kathmandu, Nepal.

Ghimire, G. 2004. HIV/AIDS awareness among Rickshaw pullers of Bharatpur municipality, Chitwan. MA Thesis. Central Department of Rural Development, Tribhuvan University, Kathmandu, Nepal.

Gurubacharya, D.L. and Gurubacharya, V.L. 2004. HIV prevalence among Nepalese migrant workers working in Nepal and Indian cities. Journal of Nepal Medical Association 43: 178-181

He, N., Zhang, J., Yao, J., Tian, X., Zhao, G., Jiung, Q. et al. 2009. Knowledge, Attitude and Practices of Voluntary HIV counseling and Testing among rural migrants in Shanghai, China. AIDS Education and Prevention 21(6): 570-581.

Iredale, R., Zhenzhen, Z. and Ko, S.H. 2005. The vulnerability of Migrants to HIV/AIDS in China and Mongolia. Asia Pacific Migration Research Network. 
Karki, L.B. 2005. Knowledge and Attitude on STDs and HIV/AIDS among Rickshaw pullers: a case study of Damak Municipality, Jhapa. M.A. Thesis. Central Department of Population Studies, Tribhuvan University, Kathmandu, Nepal.

Kouta, C., Phellas, C. and Charis, K. 2013. Knowledge Attitude and Perceptions of immigrants from third countries in Cyprus, on HIV/AIDS and sexual reproductive health. The implications of Nursing Ethics to Healthcare. Health Science Journal 7(3): 258-268.

Nepal, B. 2007. Population mobility and spread of HIV across the Indo-Nepal border. National centre for social and Economic Modelling, University of Canberra, Australia.

New Era and SATCTS. 2008. Integrated Biological and Behavioural Surveillance Survey among Male Labour Migrants in 11 Districts in Western and Mid to Far-Western Regions of Nepal, Round II. New Era and SATCTS STD/AIDS Counselling and Training Services, Kathmandu, Nepal.

Poudel, K.C. 2001. HIV/STIS risk behaviours among migrants and non-migrants in Doti district. A report submitted to Japan International cooperation Agency (JICA), Kathmandu, Nepal.

Poudel, K.C., Tandukar, K and Jimba, M. 2006. HIV/ AIDS Vulnerability of Nepali Migrants to India: Whose Concern? Lancet 368 (9548): 1648

Rai, R.K. 2005. Knowledge and Behaviour of STDs and HIV/AIDS among minibus drivers: a case study of Kathmandu Metropolitan city. M.A. Thesis. Central Department of Population Studies, Tribhuvan University, Kathmandu, Nepal.

Rayamajhi, S.B. 2000. A case study on HIV/AIDS awareness of Badi commercial sex workers at Chandani Chowk community in Bardiya district. M.A. Thesis. Patan Multiple Campus, Tribhuvan University, Lalitpur, Nepal.

Shah, N.J. 2003. Knowledge, Attitude and Practices on HIV/AIDS/STI among FSWs working in Makwanpur, Bara and Parsa highway routes: M.A. Thesis. Patan Multiple Campus, Tribhuvan University, Lalitpur, Nepal.
Sharma, A.N. 2005. AIDS in the Far west region of Nepal: a case study of cause and effect relationship of HIV/AIDS in Kanchanpur district. M.A. Thesis. Central Department of Population Studies, Tribhuvan University, Kathmandu, Nepal.

Silverman, J.G., Decker. M.R, and Gupta J. 2007. HIV Prevalence and Predictors of Infection in Sex Trafficked Nepalese Girls and Women. Journal of American Medical Association 298(5): 536-542.

Thapa, N. 2003. Knowledge, Attitude and Behaviour about STDs and HIV/AIDS of Far Eastern male returnee workers of seasonal emigrants to India: a case study of emigrants of Kanchanpur and Kailali boarder. M.A. Thesis. Central Department of Population Studies, Tribhuvan University, Kathmandu, Nepal.

Thu, M., Kyu, H.H. and Putten, M.V. 2004. Knowledge Attitude and Practices on HIV/AIDS present among Myanmar migrant in Maha Chai, Samut Sukhon Province, Thailand. Faculty of Nursing Science, Assumption University, Bangkok, Thailand.

UNAIDS. 2012. Core slides: Global Summary of the AIDS epidemic. Joint United Nations Programme on HIV/AIDS, Geneva, Switzerland.

UNICEF. 2001. A survey of teenagers in Nepal for life skills development and HIV/AIDS prevention. United Nation Children's Fund. Kathmandu, Nepal.

UNGASS. 2010. Country Progress Report. United Nations General Assemly Special Session on AIDS, Government of Nepal.

Vaidya, N.K. and Jianhong, W. 2011. HIV epidemic in far western Nepal: effect of seasonal labour migration to India. Journal of Biomedical Central Public Health 11: 1-11.

World Bank and UNAIDS. 2009. 20 Years of HIV in Bangladesh: Experiences and Way Forward. Washington, D.C., U.S.A.

Wasti, P.S., Simkhada, P., Randall, J. and Teijlingen, V.E. 2009. Issues and Challenges of HIV/ AIDS Prevention and Treatment Programme in Nepal. Global Journal of Health Science 2: 62-72 